asked. 'Why would anyone consent to this, and how could a field trial be done without consent of the local population?' Spielman also noted that 30 years ago when the WHO tried to release sterilised mosquitoes in the Indian countryside, the local population were so suspicious of the project that it was ultimately called off. $\mathrm{He}$ is also somewhat cynical about the funding of genetic engineering; he believes that's where the money is currently for research, which has attracted researchers, but that it is little more than a passing fad.

'My biggest concern in working with the genome of these vectors is that parasites have a genome, too; who's to say that the parasite won't be able to mutate in response to a changing host genome?' asked Bruce Christensen. Most researchers in the area are examining the response of the vector to the parasite, but fewer are looking at the parasite's response to the vector, which he believes is an area worthy of attention. 'There's been a lot of co-evolution between the two organisms, with different strains developing in different areas', Christensen said. 'We are a long way from impacting vector-borne infections, but I'm the last to say it won't work', he added.

\section{Vicki Brower}

DOI: 10.1093/embo-reports/kve218

\title{
Salt of the Earth
}

\section{Genetic engineering may help to reclaim agricultural land lost due to salinisation}

During medieval times, salt was a precious commodity that was traded weight for weight with gold. Arab traders with salt caravans of up to 300 camels crossed the desert for days to communities such as the mystical Timbuktu, which rose to glory because of this lucrative transSaharan salt trade.

But salt can be more of a threat than an asset, and it lies at the heart of one of today's major agricultural problems. Excess salinity in soil has devastating effects on plant growth, reducing crop yields worldwide and even leading to complete crop failure in the worst-affected areas. To overcome these limitations, plant breeders have long been trying to generate more salt-tolerant crops, largely without success. Now, researchers from the University of Toronto and the University of California in Davis have genetically engineered plants to withstand significantly higher salt concentrations than their wild-type counterparts. Through the manipulation of just one gene, they have shown that plants are able to thrive in saline conditions that would otherwise be sufficient to class a soil as useless.

Salinisation is indeed a growing problem worldwide. Christopher Leaver of the Department of Plant Sciences in Oxford, referring in particular to Western Australia, commented, 'I have seen the problems of dry land salinisation and it is frightening'. And it comes at a time when food production is under great pressure. Global food supply is at risk from farming

methods that have degraded soils, depleted aquifers, polluted waters and caused the loss of animal and plant species. With the projected increase in population of 1.5 billion people over the next two decades coupled to increased urbanisation in developing countries, world agriculture is faced with an enormous challenge simply to maintain, let alone increase, our present level of food production. Ways must be found to achieve this without resorting to unsustainable farming practices and without major increases in the amount of new land under cultivation, which would further threaten forests and biodiversity. It is estimated that productivity will need to increase by $20 \%$ in the developed world and by $60 \%$ in the developing world; therefore, the best possible use must be made of these once productive soils.

Salinisation can take one of two forms: primary salinity is due to 'natural' causes

Productivity will need to increase by $20 \%$ in the developed world and by $60 \%$ in the developing world and so the best possible use must be made of these once productive soils

such as salt carried in the air, while secondary salinity is due to man's effect on the environment. The latter problem is larger and more widespread since changing land use and management in connection with industrialised agriculture has often disturbed the delicately balanced salt cycle of the earth.

Secondary salinisation stems most often from the over-irrigation of land, which is ironic given that this commonly occurs in countries where water supply is a problem. In order to remove the uncertainty of an erratic climate, the standard practice in many arid and semi-arid zones of the world is to irrigate agricultural land with fresh water on a regular basis (see Figure 1). This water contains very low levels of ions such as sodium, calcium, magnesium, potassium, sulfate and chloride, and as the water evaporates, these are left behind. Poorly drained soils are a particular problem where the water rises to the surface by capillary action and the land is never well flushed.

The accumulation of salts wreaks havoc on most plants, causing dehydration due to osmotic stress and biochemical perturbations due to the influx of sodium ions. 


\section{analysis}

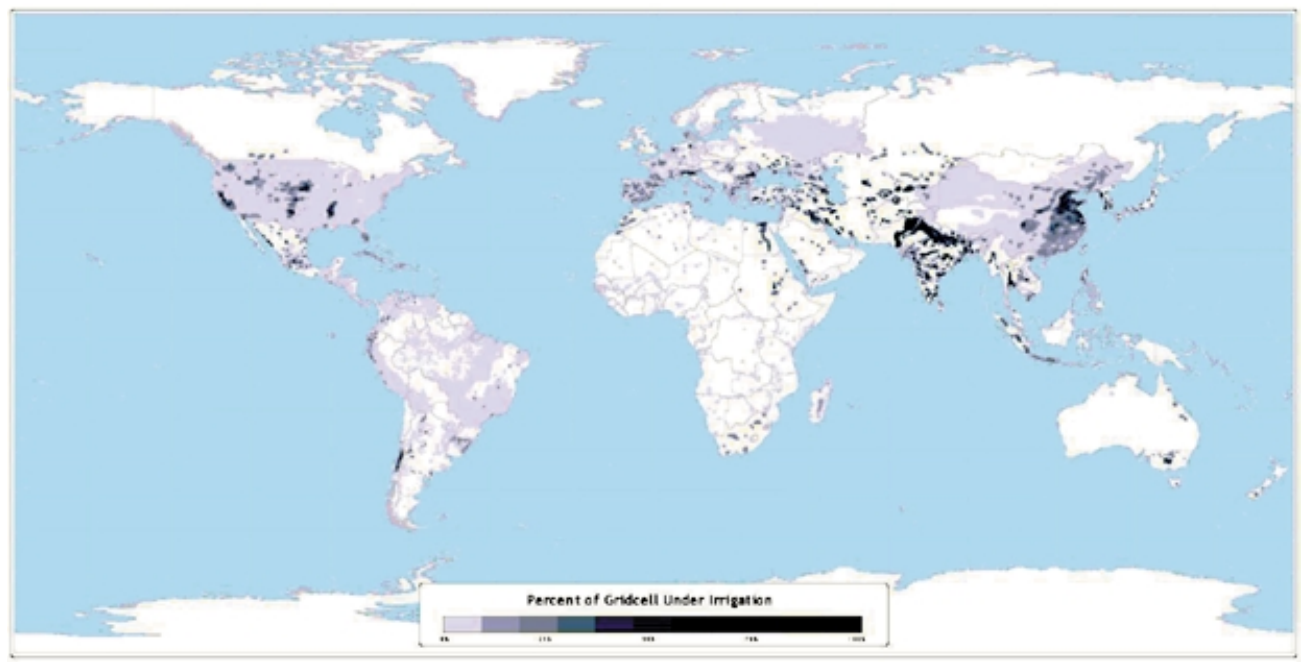

Fig. 1. The extent of the world's irrigated land. More information is available in the Atlas of the Biosphere (http://atlas.sage.wisc.edu/). Data taken from Döll, P. and Siebert, S. (2000) A digital global map of irrigated areas. ICID J., 49, 55-66.

yields are reduced on even more. Large areas of the Indian subcontinent, China's North Plain, Soviet Central Asia and parts of the Canadian prairies, the United States and Mexico are all severely affected.

In other parts of the world, secondary salinisation can develop due to the policy of clearing lands, which raises groundwater levels and brings salt to the surface. This is particularly true for Western Australia, where the fundamental cause of salinity is the replacement of perennial, deep-rooted native vegetation with shallow-rooted annual crops such as wheat. The problem is further exacerbated by primary salinisation where salt in sea spray is carried inland by prevailing winds and deposited by rainfall at a level of up to $200 \mathrm{~kg} / \mathrm{ha} / \mathrm{year}$ in some coastal areas. The Dryland Salinity Assessment 2000 published by the Australian National Land and Water Resources Audit (http://audit.ea.gov.au/anra/land/docs/ national/Salinity_Contents.html) referred to its findings as a 'wake-up call' and stated that 'Australia is a vastly different continent to Europe and we need to change our European-based farming systems to work within the context of Australian soils, water resources and climate'. Currently, $\sim 10 \%$ of Western Australia's land is classified as affected (where potential yield is reduced by $>50 \%$ ) and this figure is projected to rise to $17 \%$ between 2010 and 2020, plateauing within 50 years at a potentially devastating $32 \%$. Images as depicted in Figure 2 are commonplace. Phil Cocks from the University of Western Australia and an expert on salinity stress commented, 'Two million hectares of land in southwestern Australia are currently rendered less productive by salinity and a further 6 million are at risk. To address the problem, action is needed on most of the privately owned land in the region. In Australia as a whole, the National Farmers Federation and the Australian Conservation Foundation reckon that $\$ 65$ billion of public and private investment is needed over the next 10 years'.

Over the last 50 years, crop breeders have been trying to cross salt-tolerant halophytes with salt intolerant glycophytes in order to produce cultivatable but more salt-tolerant progeny, but without success. To genetically engineer such a plant also seemed a formidable task since it was widely believed that salt resistance was due to a whole array of interacting gene products. However, plant scientists in Toronto and California have recently made a significant breakthrough and engineered a tomato to grow in water containing 200 $\mathrm{mM}$ salt-50 times higher than plants can normally tolerate and almost half as salty as seawater. And all through the increased expression of just one gene.

Back in 1999, the group isolated the gene coding for the membrane transporter AtNHX1 from Arabidopsis thaliana. This $\mathrm{Na}^{+} / \mathrm{H}^{+}$antiport pumps sodium ions into the plant vacuole and their latest experiments published in the August issue of Nature Biotechnology clearly demon- strated that over-expression of the transporter in transgenic tomatoes significantly protects the plants in a salty environment. The sequestration of sodium away from the cytosol prevents perturbation of normal cellular metabolism and the osmotic gradient created causes the plants to take up water more effectively. The fruit tastes identical, the scientists claim, because the higher amount of sodium ions is matched by an increase in other osmotic active compounds, most notably sugars. Eduardo Blumwald who leads the group of researchers is now aiming to adapt this technology to other commercial crops. 'I've already transformed tomato, tobacco and Canola. I believe I can transform any crop with this gene $^{\prime}$. Field trials are now planned for which the researchers are still seeking funding.

Given all the unsuccessful attempts, Blumwald's approach seems strikingly simple and elegant. 'It's not the gene which is simple, but the hypothesis', commented Blumwald. 'Growth is a nonreversible thermodynamical process, once a step is taken the plant cannot go back. Thus, the use of energy is critical. That's why our work appears to be so simple. What we are doing is giving the plant the chance to use a very cheap osmoticum-sodium ions in the vacuole-to drive water uptake'. However, to an outsider it could still appear strange that natural selection has not promoted the over-expression of this gene if the effects are so dramatic. Blumwald prefers to see it the other way around. 'Plants 


\section{analysis}

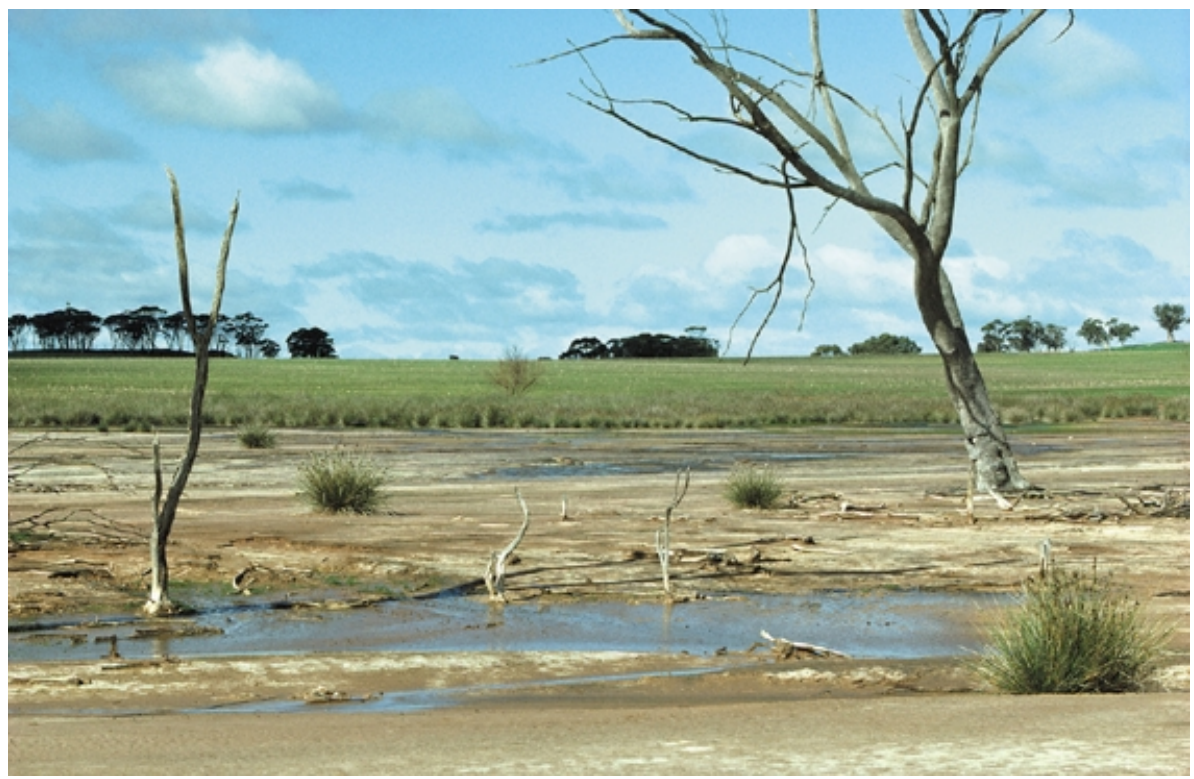

Fig. 2. Salinity-affected soils in Western Australia. Photography by Bill van Aken @ CSIRO Land and Water.

started in salty water. But then humans appeared and started 'domesticating' the wild type plants (most of which were salt tolerant) in order to get bigger fruits, more seeds and grains and we grew them in low salt conditions'. In other words, selection by conventional plant breeding is the root cause of the now minimal antiport expression seen in most cultivated plants.

These findings have generated a flurry of media interest and Christopher Leaver is not alone in believing that 'this is potentially a very important discovery which suggests that under the high salt growth conditions used by Blumwald, over-expression of a single protein can produce salt tolerant plants which retain the ability to produce edible crops'. Not only do the tomatoes thrive in the saline conditions, they also actively take up excess salt into their leaves. The possibilities, therefore, for bioremediation are obvious and indeed, Blumwald revealed that results in press show that plants can accumulate up to $6-7 \%$ of their dry weight as sodium. 'A farmer can clean the soil, grow a crop and make a profit all at the same time', he said.

While this may be the first indication of a transgenic approach to re-utilise saltstressed agricultural land, we cannot escape the fact that this is a genetically engineered plant that comes with all the stigma attached to that label. But with the current political climate against GM plants, the question is whether the public would accept a plant engineered to overproduce a 'natural' endogenous protein as opposed to one producing a 'foreign' protein such as the insecticidal Bacillus thuringiensis toxin. Blumwald himself says that the public reaction to his work is mixed. 'Unfortunately the lack of information made available to the public makes it worse. Public acceptance will be a function of how clear we are. In the meantime, the only drum they hear is the anti-GMO one'. Indeed, Greenpeace and other environmental and consumer protection groups would likely be against any such introduction of transgenic plants into the environment, irrespective of the origin of the gene involved. 'Tomatoes have a high water requirement; continued irrigation of the salt-tolerant tomato is likely to only lead to further increase in the salt content of the soil,' Greenpeace International pointed out. 'The salt-tolerant tomato is a technological "quick-fix" that will not be sustainable in the long-term and may even make the problem of salinity induced by irrigation worse.'
And despite the fact that this latest discovery has been hailed as 'a breakthrough', it certainly will not be the final answer to the problem. 'Salt tolerant plants merely address the symptoms. We need to reverse the hydrological imbalance', commented Phil Cocks. 'Plant breeding, whether conventional or otherwise, is only part of the answer, and probably a small part at that. We believe that reintroducing perennials is the best longterm answer. But this means a change in farming systems and the development of new products and is therefore likely to be a long and difficult process'.

Back in California, Blumwald predicts that, with sufficient funding, it would be possible to market such salt-tolerant plants within three years. Increasing yields from marginal soils by growing transgenicallyadapted crops may not be an all-encompassing solution, but it could be one step towards solving the problem of feeding the world's rapidly growing population.

\section{Susan Owens}

DOI: 10.1093/embo-reports/kve219 